\title{
Evaluation of Arm Anthropometry for Assessing Pediatric Body Composition: Evidence from Healthy and Sick Children
}

\author{
SIRINUCH CHOMTHO, MARY S. FEWTRELL, ADAM JAFFE, JANE E. WILLIAMS, AND JONATHAN C.K. WELLS \\ The Medical Research Council Childhood Nutrition Research Centre [S.C., M.S.F., J.E.W., J.C.K.W.], Portex Anesthesia Unit \\ [A.J.], Institute of Child Health, London, WC1N 1EH, United Kingdom
}

\begin{abstract}
Arm anthropometry is used as a proxy of body composition in clinical and field research but its validity has not been established in children. To address this issue, mid-upper arm circumference (MUAC) and triceps skinfold thickness (TS) were measured in 110 healthy children aged $4.4-13.9$ y (55 boys) and 49 cystic fibrosis (CF) patients aged 8.1-13.4 y (22 boys). Reference values were arm and whole-body fat mass (FM) and fat-free mass (FFM) measured by dual x-ray absorptiometry and four-component model, respectively. Arm fat area (AFA), MUAC, and TS correlated well with arm FM $(r=0.84-0.92)$ and total FM $(r=0.78-0.92)$. Arm muscle area (AMA) and MUAC correlated well with arm FFM $(r=$ $0.68-0.82)$ and total FFM ( $r=0.60-0.86)$. After adjusting for age, sex, and height, arm anthropometry correlated strongly with FM but weakly with FFM. AFA, MUAC, and TS explained 67, 63, and 61\% of variability in total FM in healthy children and 70, 72, and $63 \%$ in CF. AMA and MUAC explained only 24 and $16 \%$ of variability in total FFM in healthy children and 33 and $28 \%$ in CF. Arm anthropometry is useful for predicting FM and ranking healthy children and patients for fatness. It has poorer success in predicting regional or total FFM. (Pediatr Res 59: 860-865, 2006)
\end{abstract}

$\mathrm{A}^{\mathrm{r}}$ rm anthropometry has been used as a proxy of body composition in both clinical and field research settings for decades. The cross-sectional AMA and AFA were introduced for the assessment of nutritional status of children in community settings $(1,2)$ and proposed to be better than direct skinfold thickness and arm circumference measurements (3). This approach has been widely accepted and used to assess nutritional status in a variety of populations including pediatric patients in hospital settings. For example, AMA and AFA were used as outcome measures to evaluate nutritional interventions in children with cancer (4) and CF (5) and for the assessment of nutritional status in sick children (6-8). Another common application in children is to predict and compare fat and lean mass in different populations with large sample sizes $(9-13)$ or to interpret the nutritional status of populations with regard to normal reference curves $(14,15)$ in research settings. Despite the evolution of body composition measurement techniques, arm anthropometry is still popular because it is inexpensive and noninvasive, and can be mea-

Received November 2, 2005; accepted January 28, 2006.

Correspondence: Sirinuch Chomtho, M.D., MRC Childhood Nutrition Research Centre, Institute of Child Health, 30 Guilford Street, London WC1N 1EH, UK; e-mail: s.chomtho@ich.ucl.ac.uk

Supported by the Medical Research Council (United Kingdom)

DOI: 10.1203/01.pdr.0000219395.83159.91 sured without difficulty in almost any situation, especially in clinical settings where time and patients' tolerance is limited. However, the validity of this simple method for assessing body composition has not been established.

The value of arm muscle and fat area as proxies for lean and fat mass relies on the theoretical assumptions that i) the arm is cylindrical in form, ii) the subcutaneous fat is evenly distributed around a circular core of muscle, and iii) TS accurately separates fat and lean components of the arm and represents twice the thickness of subcutaneous fat in the arm (2). These assumptions inevitably predispose the method to some inaccuracy. Although a few studies have reported good agreement (despite over- or underestimation) between anthropometric arm muscle and fat area and the cross-sectional area measured by ultrasonography $(16), \mathrm{CT}(17,18)$, and magnetic resonance imaging (MRI) (19), no study has explored the association between these measurements and reference methods of body composition in pediatric populations.

Our study aimed to evaluate arm anthropometric indices as proxies for regional as well as total body composition in healthy children and also in children with a condition (CF) in which nutritional problems are common and in whom simple methods for measuring body composition would be particularly relevant.

\section{SUBJECTS AND METHODS}

A total of 110 healthy children aged 4.4-13.9 y (37 aged 4-8 y, 34 aged $8-12$ y, 39 aged $12-14$ y) who were born at term were recruited as part of a body composition reference study in healthy children. Obese children according to the International Obesity Task Force (IOTF) cut-off (20) were excluded to reduce confounding from skinfold measurement errors, as were children with any medical condition likely to affect growth. All measurements were conducted during a visit to the study center by one of three investigators. Forty CF patients aged 8.1-13.4 y participated in a body composition study at the same study center. Nine patients (four boys and five girls) were remeasured after $2 \mathrm{y}$. A total of 49 body composition measurements were therefore made in this group, all by one investigator. Ethical permission was obtained from the Research Ethics Committee of the Institute of Child Health and Great Ormond Street Hospital. Written informed consent and assent was obtained from the parents and children accordingly. 
Body weight was measured with electronic scales to the nearest $0.01 \mathrm{~kg}$ and height was measured to the nearest $0.1 \mathrm{~cm}$ with a wall-mounted stadiometer (Holtain, Dyfed, United Kingdom). BMI was calculated as weight (kilograms) divided by the square of height (meters). TS was measured with Holtain calipers and MUAC was measured with a nonstretchable fiber glass insertion tape to the nearest $0.1 \mathrm{~cm}$. Mid-arm was identified as being halfway between the acromion and olecranon process. TS was measured at the same level as MUAC in triplicate and the average of the three measurements was used. All measurements were done on the left side of standing subjects.

Pubertal status was self-assessed with the use of pictures of the Tanner stages for pubic hair and breast (female) or genital (male) development and was coded as prepubertal (Tanner stage $=1$ ) or pubertal (Tanner stage $\geq 2$ ).

Calculation of arm anthropometry. From the most widely used equation $(1,2)$ assuming the arm to be cylindrical, arm anthropometric indices were calculated as follows:

$$
\begin{gathered}
\mathrm{TUA}=\mathrm{MUAC}^{2} /(4 \times \pi) \\
\mathrm{AMA}=[\mathrm{MUAC}-(\mathrm{TS} \times \pi)]^{2} /(4 \times \pi) \\
\mathrm{AFA}=\mathrm{TUA}-\mathrm{AMA}
\end{gathered}
$$

where MUAC and TS are in centimeters and TUA (total mid-upper arm area), AMA, and AFA are in square centimeters.

Regional FM and FFM by DXA. BMC, FM, and FFM were determined using a GE Lunar Prodigy whole-body scanner (GE Medical Systems, Madison, WI) in conjunction with Encore 2002 software. The instrument automatically alters scan depth depending on the thickness of the subject, as estimated from age, height, and weight. A whole-body scan was performed while the subjects were wearing light indoor clothing and no metal objects. The typical scan duration was 5-10 min, depending on subjects' height. The radiation exposure per whole body scan was estimated to be $2.2 \mu \mathrm{Sv}$, which is lower than the daily background radiation in the UK. All scans were performed and analyzed by one operator. The FM and FFM (including BMC) of both arms was obtained for comparison with anthropometric measurements. In vivo precision of regional soft tissue composition has not yet been determined in this device, as it was considered to be unethical to perform repeat scans in individual children. Previously reported precision values for DXA are $<1 \%$ for whole body lean mass and $<2 \%$ for FM in adults (21), with slightly higher in vivo precision errors for regional than total body measurements (22).

Total body FM and FFM by four-component model. Deuterium dilution. Total body water (TBW) was determined by $\mathrm{D}_{2} \mathrm{O}$ dilution with a dose equivalent to $0.05 \mathrm{~g}$ of deuterium oxide $(99.9 \%)$ per kilogram body weight. Saliva samples were obtained predose and 4-h postdose by an absorbent salivettes, frozen at $-30^{\circ} \mathrm{C}$, and then analyzed in duplicate by Iso-Analytical Ltd. (Sandbach, UK) using the equilibration method (23) and continuous flow isotope ratio mass spectrometry. The mean $\mathrm{SD}$ of deuterium analyses by this technique in the laboratory is $<2.5 \%$. For calculating TBW, it was assumed that $\mathrm{D}_{2} \mathrm{O}$ dilution space overestimated total body water by a factor of 1.044 (24). Correction was made for dilution of the dose by water intake during the 4-h equilibration period.

Air displacement plethysmography. Whole-body air displacement plethysmography was performed using the Bodpod body composition system (Life Measurement Instruments, Concord, CA), with the subject wearing a tightfitting swimming costume and a swimming cap. The principle was to measure the volume of air in the anterior chamber, using pressure changes induced by the oscillating diaphragm according to Boyle's laws of the relations between volume, pressure and temperature of gases. The machine provides raw body volume (L) for each subject from the difference between the volumes of air in this chamber, with and without the subject being present. Actual body volume was obtained after correction for the thoracic gas volume and surface area artifact by using the appropriate prediction equation for children from age, sex, weight, and height (25). This method is more acceptable and has better precision than hydrodensitometry in children (25).

Four-component model. The four-component model of body composition is robust to detect interindividual variability in the composition of FFM as well as maintaining accuracy across the range of body fat. This model divides body weight into fat, water, protein, and mineral, and hence avoids the assumption of a constant protein to mineral ratio in FFM by adding the measurement of bone mineral content from DXA. The various assumed densities of the four components were taken into account when calculating FM from the basic measurements.

$\mathrm{FM}(\mathrm{kg})=(2.747 \times \mathrm{BV})-(0.710 \times \mathrm{TBW})+(1.460 \times \mathrm{BMC})-$

$(2.050 \times \mathrm{BW})$ where BV = actual body volume in liters (from air displacement plethysmography), TBW = total body water in liters (from deuterium dilution), $\mathrm{BMC}=$ total body $\mathrm{BMC}$ in kilograms (from DXA), and $\mathrm{BW}=$ body weight in kilograms. This calculation was described in detail elsewhere (26). FFM was then calculated as the difference between body weight and FM.

Statistics. Height and BMI were converted to SD scores using 1990 UK reference data $(27,28)$. Body composition variables were compared between subgroups of subjects using independent samples $t$ test. Anthropometric data that were not normally distributed were transformed to natural log before analysis using parametric correlation (Pearson). Partial correlations were used to explore associations between arm anthropometry and regional or total body composition, after adjusting for age, sex, and height. The main analysis was conducted on both arms' composition from DXA, however, the agreement between right and left arm was tested and the analyses were repeated for the left arm only. The coefficient of determination $\left(r^{2}\right)$ values are presented. General linear models were used to determine whether the predictive value of arm measurements differed between healthy children and CF patients after adjusting for age, sex, and height. Analyses were performed using SPSS version 12 (SPSS Inc., Chicago, IL).

\section{RESULTS}

Healthy children. Characteristics of the healthy children are shown in Table 1. The number of prepubertal children was not significantly different between boys and girls. Girls were significantly taller and heavier than boys in terms of absolute measurements, SD scores, and BMI. Boys' height and BMI SD scores were representative of the general population but girls were significantly taller $(p=0.005)$ and heavier $(p<$ 0.001) compared with 1990 UK reference data. Girls had significantly more total body and arm FM than boys, but there was no statistically significant difference in FFM. Girls also had significantly higher MUAC, TS, AMA, and AFA than boys.

Arm anthropometry and $\boldsymbol{F M}$. The $r^{2}$ values are shown in Table 2. MUAC, TS, and AFA correlated strongly with both arm (correlation coefficient, $r=0.84-0.92$ ) and total body $(r=0.78-0.92) \mathrm{FM}$ and this correlation did not significantly change after adjusting for factors that have an impact on individual body composition (age, sex, and body size). The correlations were similar between boys and girls with slightly lower $r^{2}$ for total body compared with arm FM.

Arm anthropometry and FFM. Although MUAC and AMA also correlated with arm $(r=0.76$ and 0.82$)$ and total body FFM ( $r=0.79$ and 0.86$)$, correlation coefficients were considerably lower after adjusting for age, sex and body size.

The $r^{2}$ for both FM and FFM were similar after adjusting for pubertal status (prepubertal versus pubertal; results not shown). Further analysis showed that mean paired differences between DXA derived left and right arm composition were 0.008 (SD 0.037) kg, $p=0.03$ for FM and 0.015 (SD 0.106) $\mathrm{kg}, p=0.13$ for FFM and the correlations were 0.99 and 0.98 for FM and FFM, respectively. When all analyses were repeated using only left arm values as the reference, the pattern of correlations with arm anthropometry was negligibly different from using both arms values.

CF patients. Characteristics of CF children are shown in Table 1. There was no significant gender difference in age, proportion of prepubertal subjects, anthropometry, and body composition except for BMI SD score. CF girls had a lower mean BMI SD score than CF boys. In comparison to the UK 1990 data, our CF boys were significantly shorter $(p=0.016)$ 
Table 1. Characteristics of study subjects

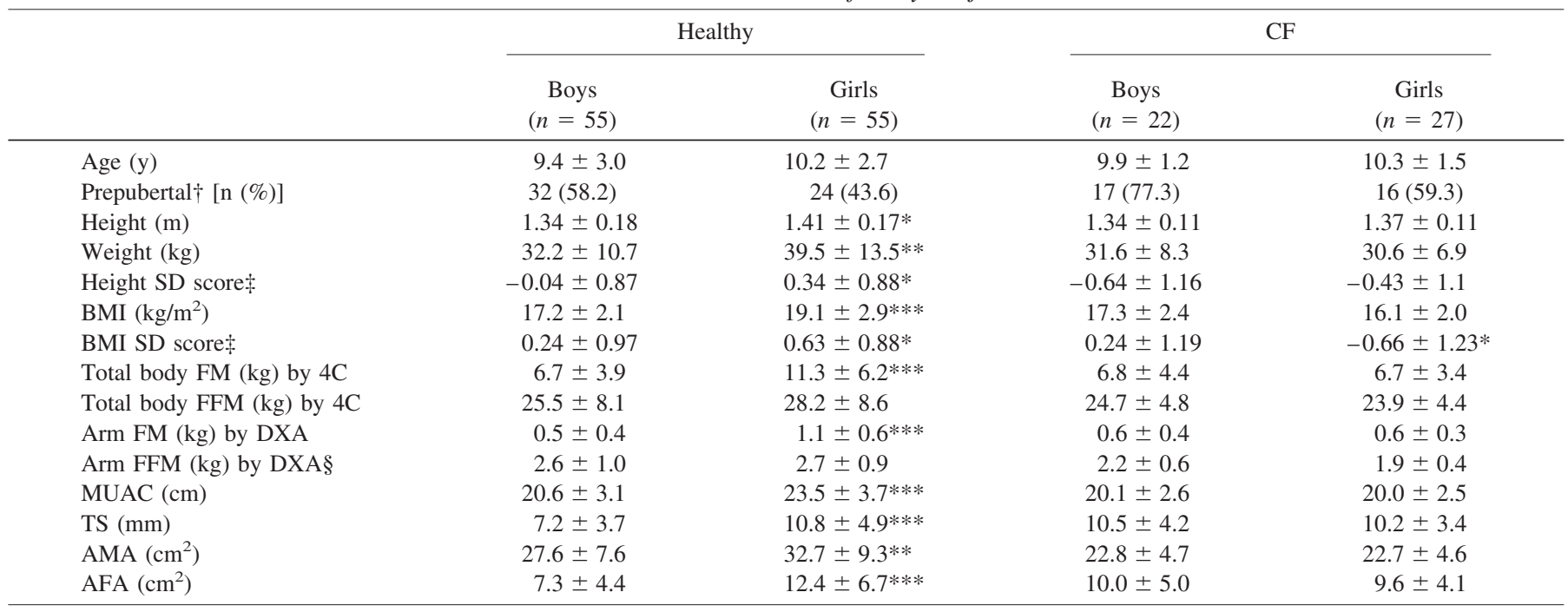

All figures are mean $\pm \mathrm{SD}$ except number of prepubertal subjects. $4 C$, four-component model.

$\dagger$ Tanner stage 1 .

$\ddagger$ Height and BMI were converted to SD scores using 1990 UK reference data.

$\S$ Including BMC.

$* p<0.05$, ** $p<0.01$, *** $p<0.001$ : significantly different from boys ( $\chi^{2}$ for number of prepubertal subjects, independent samples $t$ test for others).

Table 2. Coefficient of determination $\left(r^{2}\right)$ between arm anthropometry and body composition in healthy children

\begin{tabular}{|c|c|c|c|c|c|c|c|c|}
\hline \multirow[b]{2}{*}{ FM } & \multicolumn{2}{|c|}{$\begin{array}{l}\text { All subjects } \\
\text { No adjustment } \\
(n=110)\end{array}$} & \multicolumn{2}{|c|}{$\begin{array}{l}\text { All subjects } \\
\text { After adjusting for } \\
\text { age, sex, and height } \\
(n=110)\end{array}$} & \multicolumn{2}{|c|}{$\begin{array}{c}\text { Boys } \\
\text { After adjusting for } \\
\text { age and height } \\
(n=55)\end{array}$} & \multicolumn{2}{|c|}{$\begin{array}{c}\text { Girls } \\
\text { After adjusting for } \\
\text { age and height } \\
(n=55)\end{array}$} \\
\hline & Arms $\dagger$ & Total & Arms & Total & Arms & Total & Arms & Total \\
\hline MUAC & 0.84 & 0.84 & 0.70 & 0.63 & 0.69 & 0.58 & 0.79 & 0.72 \\
\hline TS & 0.71 & 0.60 & 0.72 & 0.61 & 0.79 & 0.67 & 0.66 & 0.58 \\
\hline AFA & 0.82 & 0.73 & 0.78 & 0.67 & 0.85 & 0.71 & 0.74 & 0.66 \\
\hline FFM & Arms & Total & Arms & Total & Arms & Total & Arms & Total \\
\hline MUAC & 0.57 & 0.62 & 0.13 & 0.16 & $0.18^{*}$ & $0.18^{*}$ & $0.14 *$ & $0.19 *$ \\
\hline AMA & 0.68 & 0.73 & 0.16 & 0.24 & $0.21 *$ & 0.23 & $0.12^{* * *}$ & 0.24 \\
\hline
\end{tabular}

Most correlation coefficients $(r)$ were significant at $p<0.001$ except: $* 0.001 \leq p<0.01, * * 0.01 \leq p<0.05$

$\uparrow$ Arm composition from DXA.

$\uparrow$ Total body composition from four-component model.

whereas CF girls were both shorter $(p=0.054)$ and lighter $(p$ $=0.010)$ than healthy children.

Arm anthropometry and $\boldsymbol{F M}$. The $r^{2}$ values are shown in Table 3. The correlations between MUAC, TS, or AFA and FM were similar to those in healthy children, with strong correlations persisting after adjusting for age, sex, and height. The results were also comparable in boys and girls.

Arm anthropometry and FFM. Correlations between MUAC or AMA and FFM were poorer than those between arm anthropometry and FM. The correlation coefficients slightly dropped after adjusting for age, sex, and height, although they were stronger when compared with those in healthy children. However, in a general linear model, there was no statistically significant interaction between disease status and either AMA or MUAC on arm or total body FFM. Arm anthropometry correlated better with FM in CF girls than boys.

The $r^{2}$ for both FM and FFM were similar after adjusting for pubertal status (prepubertal versus pubertal, results not shown). Further analysis showed that mean paired differences between DXA-derived left and right arm composition were 0.002 (SD 0.028) $\mathrm{kg}, p=0.65$ for FM and 0.008 (SD 0.070) $\mathrm{kg}, p=0.43$ for FFM and the correlations were 0.99 and 0.96 for FM and FFM, respectively. Again, when all analyses were repeated using only left arm values as the reference, the pattern of correlations with arm anthropometry was negligibly different from using both arms values.

Examples of scatter plots showing the relationship between arm fat and muscle area and body composition for all CF children are shown in Figure 1. The scatter of data between arm anthropometry and FM was tighter than that for FFM. Scatter plots for MUAC, TS in CF and equivalent plots in healthy children showed a similar pattern.

\section{DISCUSSION}

Our data suggest that arm anthropometric measurements and calculated indices are good for predicting regional and total body FM but not FFM. Additionally, there is no obvious 
Table 3. Coefficient of determination $\left(r^{2}\right)$ between arm anthropometry and body composition in CF patients

\begin{tabular}{|c|c|c|c|c|c|c|c|c|}
\hline \multirow[b]{2}{*}{ FM } & \multicolumn{2}{|c|}{$\begin{array}{c}\text { All subjects } \\
\text { No adjustment } \\
(n=49)\end{array}$} & \multicolumn{2}{|c|}{$\begin{array}{c}\text { All subjects } \\
\text { After adjusting for } \\
\text { age, sex, and height } \\
(n=49)\end{array}$} & \multicolumn{2}{|c|}{$\begin{array}{l}\text { Boys } \\
\text { After adjusting for } \\
\text { age and height } \\
(n=22)\end{array}$} & \multicolumn{2}{|c|}{$\begin{array}{c}\text { Girls } \\
\text { After adjusting for } \\
\text { age and height } \\
(n=27)\end{array}$} \\
\hline & Arms $\dagger$ & Total $\neq$ & Arms & Total & Arms & Total & Arms & Total \\
\hline MUAC & 0.83 & 0.77 & 0.78 & 0.72 & 0.75 & 0.78 & 0.85 & 0.67 \\
\hline $\mathrm{TS}$ & 0.73 & 0.62 & 0.75 & 0.63 & 0.77 & 0.70 & 0.73 & 0.61 \\
\hline AFA & 0.82 & 0.71 & 0.82 & 0.70 & 0.82 & 0.77 & 0.82 & 0.67 \\
\hline FFM & Arms & Total & Arms & Total & Arms & Total & Arms & Total \\
\hline MUAC & 0.46 & 0.36 & 0.39 & 0.28 & $0.29 * *$ & $0.19 * * * *$ & 0.52 & $0.34 *$ \\
\hline AMA & 0.51 & 0.43 & 0.42 & 0.33 & $0.38^{*}$ & $0.36^{*}$ & 0.47 & $0.31 *$ \\
\hline
\end{tabular}

Most correlation coefficients $(r)$ were significant at $p<0.001$ except: $* 0.001 \leq p<0.01, * * 0.01 \leq p<0.05, * * * p \geq 0.05$.

$\uparrow$ Arm composition from DXA.

† Total body composition from four-component model.
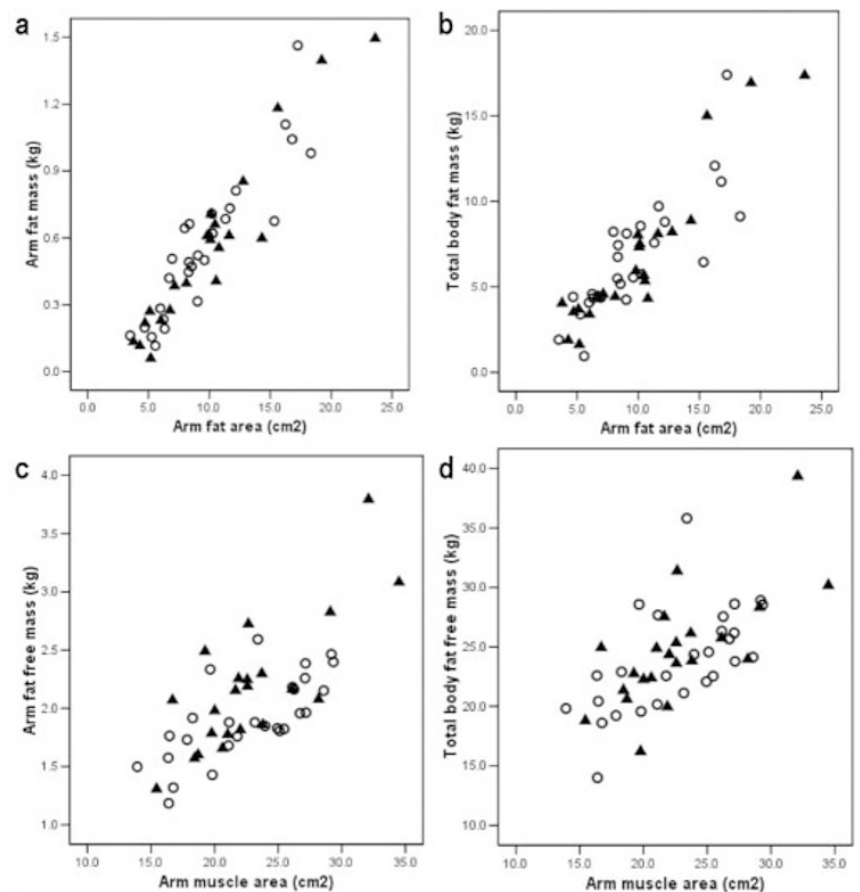

Figure 1. Scatter plot of relationship between arm fat and muscle area and body composition in CF patients $(n=49)$. (a) Relationship between AFA and DXA arm FM. $r^{2}=0.82, p<0.001 ;(b)$ Relationship between AFA and total FM (4C). $r^{2}=0.71, p<0.001 ;(c)$ Relationship between AMA and DXA arm FFM. $r^{2}=0.51, p<0.001 ;(d)$ Relationship between AMA and total FFM (4C). $r^{2}=0.43, p<0.001$. $\mathbf{\Delta}$, boy; $\bigcirc$, girl.

benefit from calculating the more complicated indices such as AFA because TS or MUAC gave similar $r^{2}$ for predicting FM. The proportion of variability in FFM that can be accounted for by arm anthropometry is higher in CF patients than in healthy children. However, there was no statistical interaction between disease and either AMA or MUAC on FFM, suggesting that the predictive value of arm anthropometry does not differ significantly in healthy children and those with CF. In general, $r^{2}$ values for predicting total body FM or FFM tend to be lower than those predicting arm composition. This shows that good measurement or prediction of arm composition does not necessarily represent good prediction for total body composition. In CF girls, for example, arm anthropometry can account for approximately half of the variability in arm FFM but only one third for total body FFM.

Because calculation of AMA and AFA is based on theoretical assumptions as described previously, several attempts have been made to modify the calculation and make it closer to cross-sectional values obtained by CT or MRI $(18,19)$. The most well-known revised equation is the bone-free AMA proposed by Heymsfield et al. (18). This equation subtracts midarm bone area (a constant value according to sex in adults) from the original equation on the basis that bone does not atrophy in proportion to muscle in severe wasting and that the original equation tends to overestimate AMA when compared with CT. However, this correction as it stands could not be applied in a pediatric population because of the greater variation in bone size. Therefore, in our study we used arm FFM, which includes bone and fat-free soft tissue to provide a reasonable comparison with anthropometric AMA, which also includes bone area.

Most studies attempting to explore the relationships between arm anthropometry and direct measurements of body composition have been done in adults. Reid et al. (29) found that MUAC, TS, and AMA correlated more strongly with fat than with lean mass in postmenopausal women. Kwok et al. (30) showed similar findings in an older Chinese population. Jeong et al. (31) demonstrated that in adults with cirrhosis who had diminished body fat, there was close correlation between AFA and FM but not AMA and lean mass. All three studies used DXA as the reference method for body composition (FM and lean soft tissue mass). Although these analyses were done without age or body size adjustment, their conclusions seem to agree with our study. This could possibly be explained by the narrow range of body size in these homogenous groups of adults compared with a pediatric population.

Our finding that correlations between arm anthropometry and FFM significantly decreased by about half after size adjustment suggests that the high correlation coefficients observed in some populations with a wide range of body size might arise from the strong relationship between both arm anthropometry and body composition and body size. For instance, a study by Heymsfield et al. (32) using dual-photon absorptiometry to quantify limb skeletal muscle mass in 34 adult volunteers (without body size adjustment) was the only 
study that showed a strong correlation between AMA and limb muscle mass $(r=0.92 ; p<0.001)$. In other words, without size adjustment, a strong correlation can only show that AMA ranks individuals according to their body size, not necessarily their body composition i.e., bigger people would have larger AMA but not necessarily relatively more FFM. For the pediatric population, when body size is changing dramatically and in whom growth is a very important factor for body composition change, age and body size should always be taken into account. In our study, height was used as an index of body size instead of weight or BMI because the latter is not independent from FM or FFM (e.g., FM is a part of body weight) (33) and could result in bias in the analysis of correlation.

In children, only one study comparing AMA and a surrogate marker of muscle mass such as creatinine excretion (34) has been done so far. Another study investigated the efficacy of AFA in estimating total body fat by hydrostatic weighting in a group of healthy individuals with wide age range from 6 to $50 \mathrm{y}$ (35). The results were quite similar to our study in that skinfold thickness and AFA strongly correlated with fatness but the researchers suggested that AFA was better than skinfolds in estimating FM. Nevertheless, this study did not take body size into account in the analysis and only used a twocomponent model of body composition as the reference method.

For total body composition, our study is the first that validates arm anthropometry against the four-component model, which is considered to be the "gold standard" for body composition at present. However, the accuracy of DXA for determining regional body composition is still under investigation. Elia et al. (36) showed that DXA better predicted limb muscle mass as measured by MRI than bedside techniques (anthropometry and bioelectrical impedance analysis). Although it has some limitations for measurement of soft tissue composition, DXA is still a practical method for measuring regional body composition when compared with gold standards such as MRI and CT, which are more complicated, expensive, and, in the case of $\mathrm{CT}$, involve more radiation exposure. DXA-derived arm FM and FFM can therefore reasonably be used as reference measurements for regional body composition in children. In this study, we used DXA values for both arms as the reference for regional FM and FFM because we believed that it could lessen the error due to landmarks that separate the arm regions from thigh and trunk. Further analysis showed good agreement between left and right arm DXA-derived FM and FFM and the pattern of correlations with arm anthropometry was comparable to that obtained when DXA left arm values alone were used as the reference.

It should be noted that all correlations in our study are shown in the form of $r^{2}$ rather than $r$ because it demonstrates more clearly the proportion of variability of the predicted outcome (body composition) that can be explained by potential predictors (arm anthropometry). For example, AMA showed significant correlation with total body FFM in CF patients $(r=0.58 ; p<0.001)$, but when $r^{2}$ is calculated, the variability in total body FFM that could be accounted for by
AMA was only one-third (33\%). It is therefore important in this situation to consider the meaning of $r$ and $r^{2}$ rather than the $p$ value, which is usually significant with large sample sizes.

Our study explored the association between arm anthropometry and body composition in two different pediatric populations-healthy children and those with a chronic disease- to determine the value of the indices in both a field research and a clinical setting. Despite the use of the best available reference methods and adjustments for age and size, extrapolation of these results into wider populations should be undertaken with caution. Our population consisted of healthy children and reasonably well-nourished patients in the age range from 4 to $14 \mathrm{y}$ old so the results could not be applied to neonates and infants or to severely malnourished children where the relationship between arm anthropometry and body composition might be different. For example, a study from sub-Saharan Africa showed that MUAC was a practical screening tool in predicting subsequent inpatient mortality among severely malnourished children (37).

In conclusion, simple arm anthropometry is useful for predicting FM and ranking healthy children and patients in terms of fatness. Unfortunately, both MUAC and AMA have poorer success as predictors for regional or total body FFM and the use of these indices in body composition assessment should be interpreted cautiously. However, determination of FFM is still very important in both research and clinical practice and current reference methods for measuring regional or total body FFM are not usually practical in clinical or field research settings. Other simple or bedside techniques for predicting FFM warrant further investigation.

Acknowledgments. The authors thank the children and their parents for participating in the study and Catherine M Wilson for conducting and analyzing all DXA scans. SC, JCKW, and MSF designed the study and analyzed the data. AJ provided advice and recruitment of CF patients. JEW and SC measured the subjects and modeled the body composition data. SC prepared the first draft of the manuscript. All the authors contributed to revision of the manuscript. None of the authors has any conflicts of interest.

\section{REFERENCES}

1. Jelliffe DB, Jelliffe EF 1961 The nutritional status of Haitian children. (Report of a field survey). Acta Trop 18:1-45

2. Frisancho AR 1974 Triceps skin fold and upper arm muscle size norms for assessment of nutrition status. Am J Clin Nutr 27:1052-1058

3. Frisancho AR 1981 New norms of upper limb fat and muscle areas for assessment of nutritional status. Am J Clin Nutr 34:2540-2545

4. Rickard KA, Becker MC, Loghmani E, Grosfeld JL, Godshall BJ, Weetman RM, Coates TD, Lingard CD, White NM, Foland BB 1989 Effectiveness of two methods of parenteral nutrition support in improving muscle mass of children with neuroblastoma or Wilms' tumor. A randomized study. Cancer 64:116-125

5. Bertrand JM, Morin CL, Lasalle R, Patrick J, Coates AL 1984 Short-term clinical, nutritional, and functional effects of continuous elemental enteral alimentation in children with cystic fibrosis. J Pediatr 104:41-46

6. Todorovska L, Sahpasova E, Todorovski D 2002 Anthropometry of the trunk and extremities in nutritional assessment of children with chronic renal failure. J Ren Nutr 12:238-243

7. Taskinen M, Saarinen-Pihkala UM 1998 Evaluation of muscle protein mass in children with solid tumors by muscle thickness measurement with ultrasonography, as compared with anthropometric methods and visceral protein concentrations. Eur J Clin Nutr 52:402-406 
8. Edefonti A, Picca M, Damiani B, Garavaglia R, Loi S, Ardissino G, Marra G, Ghio L 2001 Prevalence of malnutrition assessed by bioimpedance analysis and anthropometry in children on peritoneal dialysis. Perit Dial Int 21:172-179

9. Manshande JP, Vuylsteke J, Vlietinck R, Eeckels R 1985 Arm muscle and fat in the evaluation of nutritional status. A study of African pre-school children in three different environments. Eur J Pediatr 144:32-36

10. Hediger ML, Overpeck MD, Kuczmarski RJ, McGlynn A, Maurer KR, Davis WW 1998 Muscularity and fatness of infants and young children born small- or largefor-gestational-age. Pediatrics 102:E60

11. Bolzan A, Guimarey L, Frisancho AR 1999 Study of growth in rural school children from Buenos Aires, Argentina using upper arm muscle area by height and other anthropometric dimensions of body composition. Ann Hum Biol 26:185-193

12. Fewtrell MS, Lucas A, Cole TJ, Wells JC 2004 Prematurity and reduced body fatness at 8-12 y of age. Am J Clin Nutr 80:436-440

13. Martorell R, Yarbrough C, Lechtig A, Delgado H, Klein RE 1976 Upper arm anthropometric indicators of nutritional status. Am J Clin Nutr 29:46-53

14. Frisancho AR, Tracer DP 1987 Standards of arm muscle by stature for the assessment of nutritional status of children. Am J Phys Anthropol 73:459-465

15. Gerver WJ, de Bruin R 1996 Body composition in children based on anthropometric data. A presentation of normal values. Eur J Pediatr 155:870-876

16. Chiba T, Lloyd DA, Bowen A, Condon-Meyers A 1989 Ultrasonography as a method of nutritional assessment. JPEN J Parenter Enteral Nutr 13:529-534

17. Jordao AA, Bellucci AD, Dutra de Oliveira JE, Sergio Marchini J 2004 Midarm computerized tomography fat, muscle and total areas correlation with nutritional assessment data. Int J Obes Relat Metab Disord 28:1451-1455

18. Heymsfield SB, McManus C, Smith J, Stevens V, Nixon DW 1982 Anthropometric measurement of muscle mass: revised equations for calculating bone-free arm muscle area. Am J Clin Nutr 36:680-690

19. Rolland-Cachera MF, Brambilla P, Manzoni P, Akrout M, Sironi S, Del Maschio A, Chiumello G 1997 Body composition assessed on the basis of arm circumference and triceps skinfold thickness: a new index validated in children by magnetic resonance imaging. Am J Clin Nutr 65:1709-1713

20. Cole TJ, Bellizzi MC, Flegal KM, Dietz WH 2000 Establishing a standard definition for child overweight and obesity worldwide: international survey. BMJ 320:12401243

21. Ogle GD, Allen JR, Humphries IR, Lu PW, Briody JN, Morley K, Howman-Giles R, Cowell CT 1995 Body-composition assessment by dual-energy x-ray absorptiometry in subjects aged 4-26 y. Am J Clin Nutr 61:746-753

22. Mazess RB, Barden HS, Bisek JP, Hanson J 1990 Dual-energy x-ray absorptiometry for total-body and regional bone-mineral and soft-tissue composition. Am J Clin Nutr 51:1106-1112
23. Scrimgeour CM, Rollo MM, Mudambo SM, Handley LL, Prosser SJ 1993 A simplified method for deuterium/hydrogen isotope ratio measurements on wate samples of biological origin. Biol Mass Spectrom 22:383-387

24. Racette SB, Schoeller DA, Luke AH, Shay K, Hnilicka J, Kushner RF 1994 Relative dilution spaces of $2 \mathrm{H}$ - and 18O-labeled water in humans. Am J Physiol 267:E585-E590

25. Dewit O, Fuller NJ, Fewtrell MS, Elia M, Wells JC 2000 Whole body air displacement plethysmography compared with hydrodensitometry for body composition analysis. Arch Dis Child 82:159-164

26. Wells JC, Fuller NJ, Dewit O, Fewtrell MS, Elia M, Cole TJ 1999 Four-component model of body composition in children: density and hydration of fat-free mass and comparison with simpler models. Am J Clin Nutr 69:904-912

27. Freeman JV, Cole TJ, Chinn S, Jones PR, White EM, Preece MA 1995 Cross sectional stature and weight reference curves for the UK, 1990. Arch Dis Child 73:17-24

28. Cole TJ, Freeman JV, Preece MA 1995 Body mass index reference curves for the UK, 1990. Arch Dis Child 73:25-29

29. Reid IR, Evans MC, Ames R 1992 Relationships between upper-arm anthropometry and soft-tissue composition in postmenopausal women. Am J Clin Nutr 56:463-466

30. Kwok T, Woo J, Chan HH, Lau E 1997 The reliability of upper limb anthropometry in older Chinese people. Int J Obes Relat Metab Disord 21:542-547

31. Jeong SH, Lee JA, Kim JA, Lee MW, Chae HB, Choi WJ, Shin HS, Lee KH, Youn SJ, Koong SS, Park SM 1999 Assessment of body composition using dual energy $\mathrm{X}$-ray absorptiometry in patients with liver cirrhosis: comparison with anthropometry. Korean J Intern Med 14:64-71

32. Heymsfield SB, Smith R, Aulet M, Bensen B, Lichtman S, Wang J, Pierson RNJr. 1990 Appendicular skeletal muscle mass: measurement by dual-photon absorptiometry. Am J Clin Nutr 52:214-218

33. Wells JC, Cole TJ 2002 ALSPAC study steam adjustment of fat-free mass and fat mass for height in children aged 8 y. Int J Obes Relat Metab Disord 26:947-952

34. Trowbridge FL, Hiner CD, Robertson AD 1982 Arm muscle indicators and creatinine excretion in children. Am J Clin Nutr 36:691-696

35. Himes JH, Roche AF, Webb P 1980 Fat areas as estimates of total body fat Am J Clin Nutr 33:2093-2100

36. Elia M, Fuller NJ, Hardingham CR, Graves M, Screaton N, Dixon AK, Ward LC 2000 Modeling leg sections by bioelectrical impedance analysis, dual-energy X-ray absorptiometry, and anthropometry: assessing segmental muscle volume using magnetic resonance imaging as a reference. Ann N Y Acad Sci 904:298-305

37. Berkley J, Mwangi I, Griffiths K, Ahmed I, Mithwani S, English M, Newton C, Maitland K 2005 Assessment of severe malnutrition among hospitalized children in rural Kenya: comparison of weight for height and mid upper arm circumference. JAMA 294:591-597 